\title{
Simulation Analysis and Improvement of the Vehicle Queuing System on Intersections Based on MATLAB
}

\author{
Fuyu Wang ${ }^{1,2 *}$, Chunming $\mathrm{Ye}^{1}$, Yanan Zhang ${ }^{2}$ and ${\mathrm{Yan} \mathrm{Li}^{2}}^{2}$ \\ ${ }^{I}$ Management School, University of Shanghai for Science \& Technology, Shanghai, China; ${ }^{2}$ School of Management Sci- \\ ence \& Engineering, Anhui University of Technology, Anhui, China
}

\begin{abstract}
In order to reduce the traffic congestion and to enhance the capacity of urban road intersections, this paper builds a model of the vehicle queuing system for the intersection by queuing theory Based on Monte Carlo algorithm, this paper carries out simulation and analysis of the vehicle queuing system in the intersection by MATLAB, analyses, the status of vehicle queue to reduce the vehicle queue waiting time, and explores methods to solve the problem of vehicle queues at intersections. The optimal design for vehicle operating conditions has also been implemented from the perspective of the queuing theory, facilities planning, Ergonomics and the management system. The results show that the analysis and improvement to the existing access program of the intersection can effectively relieve the vehicles queuing problem and promote the social service intensity of urban transportation system.
\end{abstract}

Keywords: MATLAB, monte carlo algorithm, simulation analysis, the vehicle queuing system.

\section{INTRODUCTION}

With the rapid growth in urbanization and the rapid development of China's economy, there has been a massive growth in the number of motor vehicles on the road, which has led to an increase in the urban traffic, this has given birth to increased pressure on the urban roads. This phenomena has also increased the demand for building a scaled up urban road system. So far, the investments regarding the old urban roads' reconstruction have continued to expand. However, because there has been a faster growth in the population of urban motor vehicle, the traffic demand has become far greater than the supply. As a result that the urban road network has become overloaded. The urban traffic continues to increase in congestion, road intersections often result in the vehicles waiting in line and the intersections get even more crowded during peak hours. As a consequence congestion and accidents have increased, environmental pollution has become more serious. Overall this has become one of the most serious "urban disease" our cities are facing at the moment, this has also become a bottleneck for our country's economic development [1,2].

Our country's urban road infrastructure and development has lagged behind, prominently in some big cities facing. The main problems that exist in the urban traffic are the chaotic traffic intersections, road occupancy serious, low road capacity, backward transport facilities, people pass messy roads, mixed traffic interference and other more serious issues [3].

As the road intersections serve as the throat for the urban traffic, their capacity is much lower than the total sum capacity of all road sections entrance for the intersection. And the main reason for traffic congestion and obstruction is shortage in intersection's capacity, rather than the road capacity. Therefore, it is necessary to re-design and re-structure the structure facilities and traffic management transformation. At this time, the implementation of scientific management and control intersections is also an important measure for the protection of traffic safety and for intersection's full capacity [4].

The literature [5-8] shows that the foreign experts believe that transportation planning should precede construction layout, urban transport as a basis for one of the most important facilities, should occupy a special place in urban construction. The United States proposed a set system planning theory of transportation in 1995, which emphasizes the formularization of transportation planning, the key points of the theory state that the traffic should be allowed to flow, city's land should be used regarding the future status of the city, detailed analysis and investigation should be preformed regarding the growth trends of vehicles and transportation infrastructure. Depending on the characteristics of urban traffic in recent years, some developed countries have also made some characteristic planning theories. The most typical is the "choke points" theory which was inspired by Russia and Japan's "road junction node" theory. "Choke points" theory emphasizes the role of the transport hub points on the basis of established forms of transport line with structural frame. "Railway junction node" theory is advocated in fostering urban railway hub point spread function, to form a functional and structural system in large cities, and as a polycentric urban structure to achieve a prerequisite.

With the gradual development in smart city construction, in order to improve the urban road intersection traffic efficiency, reduce intersection vehicle carbon emissions, this 
thesis has taken the Road intersections as the research objects. Regarding the problem of vehicle queuing system, integrated use of operations research, human factors, theories and methods of management, based on Monte Carlo simulation and MATLAB software problems processing have been analyzed and optimized. Lastly, based on the above, improvement suggestions from three sides queuing theory, facilities planning and management systems [9-11] have been put forward.

\section{DATA MEASUREMENT AND STATISTICAL ANALYSIS}

\subsection{Description and Statistics Intersection}

JiangDong Road and Hunan Road intersection are fivefork intersections consisting of Jiangdong Road, Hunan Road and Huashan Road, each intersection is provided with a traffic light control device. The road junction is an important signal control intersections in the city. Over here the traffic queuing phenomena is observed quite frequently. The plane facility layout of intersection is shown in Fig. (1).

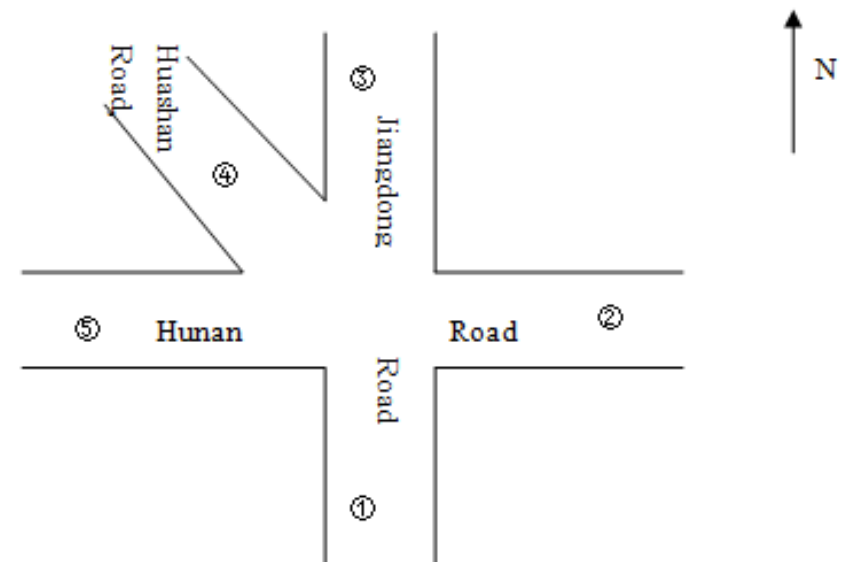

Fig. (1). The plane Facilities layout of the intersection.

Based on the principle of random sampling, after five days of on-site field research, measurements for the following factors were observed: The traffic flow on each intersection, vehicle arrival interval time, the time taken by vehicles to pass through the intersection, time and duration of each sidewalk traffic light, the changing direction of the traffic lights. After statistical processing, and the number of the vehicle reaching the desired limit, the frequency distribution table for the junction was made and obtained. The vehicle's arrival time distribution tables and vehicle service time distribution tables are shown in Tables 1-3 respectively.

\subsection{Extant Problems and Countermeasures}

(1) Collecting traffic intersection in the interval period found that the irrationality of the duration of the traffic lights junction led to crowded waiting vehicles. The vehicle's average waiting time was found to be too long. The Queuing theory can be applied using its statistical knowledge of the traffic flow, in order to improve signal's duration time.

(2) Because there are different types of motor vehicles, vehicle's length has different effect on the traffic, especially when a large truck gets parked in front of a car, it becomes very easy to block the rear sight of the vehicle, as a result it becomes impossible for the vehicle standing behind the truck to see the traffic lights change in time, this effects the rear vehicle's passing time, this even causes the rear row vehicle drivers dissatisfaction. Human factors knowledge can be applied on the traffic light system to optimize the design.

(3) Traffic lights do not have set time reminder device, which make the vehicles to realize traffic lights changes. It can be learn from the perspective of the person who set the time for the traffic lights to remind devices.

(4) Sidewalk intersection control lights are relatively unreasonable, the road is very wide, the green light, lights up for a short duration. Even when a pedestrian doesn't passes, the red light, lights up. This is extremely inconvenient especially for the elderly and children. Therefore, improvements should be made to the side walk controls.

(5) The north-south direction the traffic is more serious, east-west traffic is relatively better, however the traffic flow of the roads is not balanced, as a result on a particular part of the road traffic pressure increases. Therefore, from the perspective of improving facility layout for each single and double lane, the traffic flow should be balanced.

(6) From the point of view of spatial planning across the intersection, pedestrian and vehicle traffic is a mess, which can easily result in traffic accidents. Therefore the entire intersection's layout should be redesigned, so that pedestrians and vehicles flow in an orderly manner.

(7) Too much time delays caused by traffic congestion waste time and energy. The transport vehicles are very diverse, thus the traffic system should be coped with using scientific management system.

\section{QUEUING SYSTEM SIMULATION OF VEHICLE BASED ON MONTE CARLO METHOD}

\subsection{Monte Carlo Method}

Monte Carlo method is also known as the statistical experimental method, which is based on the probability theory and mathematical statistics for simulation guidance. The advantage for this method is that it doesn't relies on any specific form of the simulation limit state equations. And it is independent of any distribution form of the variable, convergence rate independent random variables dimension, and the simulation error can be determined. The disadvantages are that, high precision requires a very large number of simulations and therefore can lead to a large amount of calculation, as a result the calculation time becomes longer. However, with the accelerated computing speed, using the Monte Carlo method is also more extensive.

The basic steps are as follows:

(1) Statistical data analysis and processing to meet the modeling needs.

(2) Establish a probabilistic model, that is, the researched issues to construct a probability model corresponding its characteristics, turn the uncertainty problem into probability issues, and establish a probability model. 
Table 1. The number of vehicles to reach a frequency distribution table.

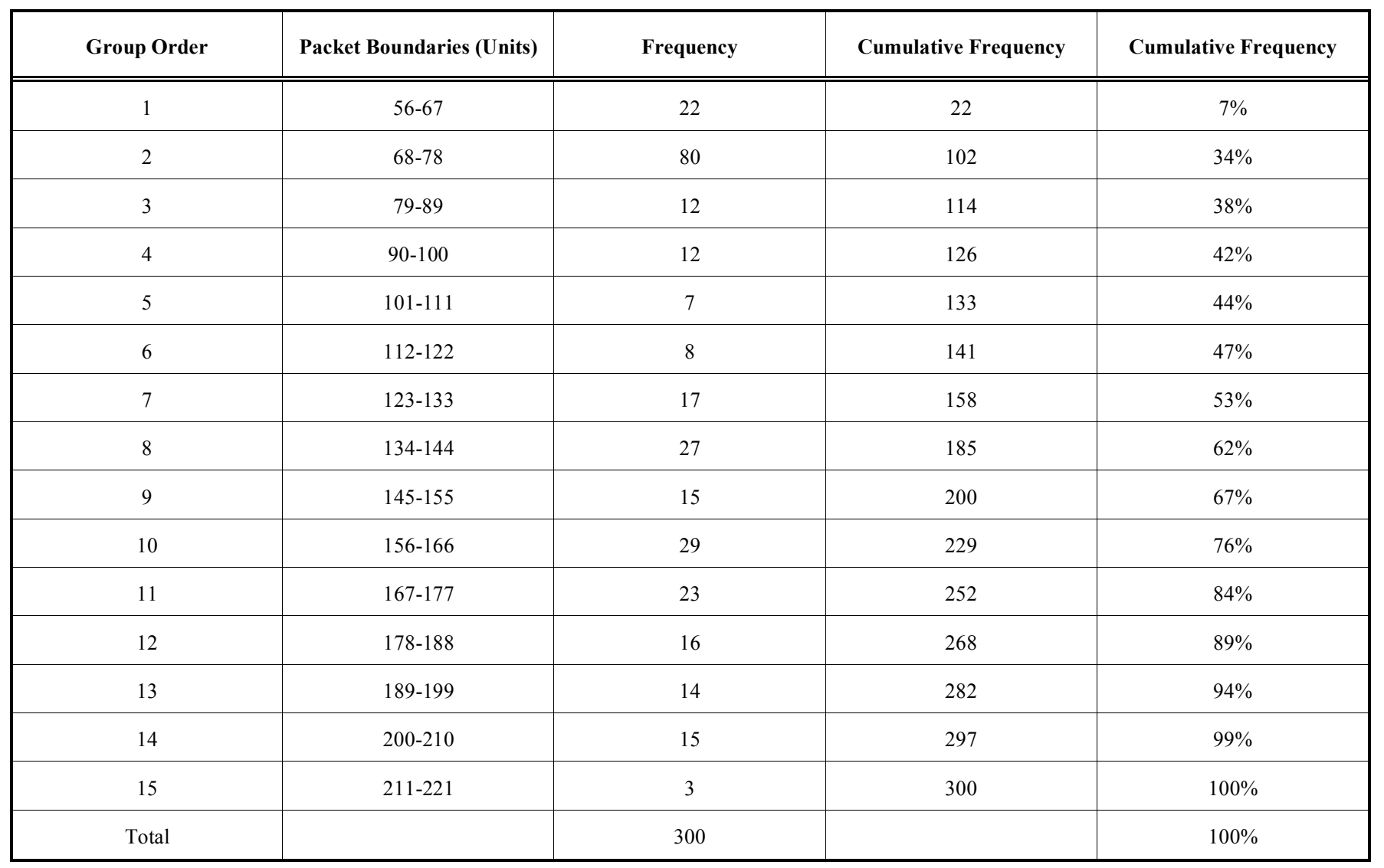

Table 2. Successive vehicle arrival time distribution.

\begin{tabular}{|c|c|c|c|c|c|}
\hline \multirow{2}{*}{$\begin{array}{l}\text { Successive Intervals of Time } \\
\text { the Vehicle Reaches (s) }\end{array}$} & \multicolumn{5}{|c|}{ Occurrence } \\
\hline & (1) Intersection & (2) Intersection & (3) Intersection & (4) Intersection & (5) Intersection \\
\hline $3.4-6.4$ & 34 & 23 & 30 & 31 & 33 \\
\hline $9.4-12.4$ & 4 & 12 & 5 & 11 & 11 \\
\hline $12.4-15.4$ & 6 & 6 & 1 & 4 & 5 \\
\hline $15.4-18.4$ & 1 & 2 & 1 & 2 & 8 \\
\hline $18.4-21.4$ & 3 & 2 & 2 & 3 & 1 \\
\hline $27.4-30.4$ & & 1 & 1 & 1 & 1 \\
\hline $30.4-33.4$ & & & 1 & 0 & 1 \\
\hline $33.4-36.4$ & & & & 1 & \\
\hline Total & 98 & 98 & 97 & 97 & 97 \\
\hline
\end{tabular}


Table 3. Vehicle service time distribution table.

\begin{tabular}{|c|c|c|c|c|c|}
\hline \multirow{2}{*}{ Vehicle Service Time v (s) } & \multicolumn{5}{|c|}{ Occurrence } \\
\cline { 2 - 6 } & (1) Intersection & (2) Intersection & (3) Intersection & (4) Intersection & (5) Intersection \\
\hline \hline $0-4$ & 44 & 46 & 45 & 44 & 23 \\
\hline $4-8$ & 30 & 26 & 29 & 17 & 10 \\
\hline $8-12$ & 14 & 14 & 13 & 10 & 10 \\
\hline $12-16$ & 5 & 8 & 9 & 5 & 100 \\
\hline$>16$ & 7 & 6 & 4 & 100 & 5 \\
\hline
\end{tabular}

(3) Generate a random number sequence, the input sampling system as the simulation test, analyses the test results and using the variation of the system.

\subsection{Simulation Model}

Set up $t_{i}$ for the $i$ car arrival time; $\zeta$ for the $i$ car arrival interval, it is usually a random number; $t_{i S}$ for the $i$ car service start time; $t_{i E}$ for the $i$ car service completion time; $\eta$ for the $i$ car service time, which is usually a random number; $t_{i W}$ for the $i$ car waiting time; $t_{i t}$ for the $i$ car duration of stay of the car; $l_{s i}$ for the $i$ car service period the number of vehicles in the system, $l_{q i}$ for the number of vehicles in the queue, $l_{i}$ for the number of vehicle being serviced.

(1) Say that the vehicle reaches the interval and service time

Service intervals and vehicle arrival time are uncontrollable variables, using the Monte Carlo method we can generate random numbers.

(2) Arrival time for

$t_{1}=\zeta ; t_{i}=t_{i-1}+\zeta \quad i \geq 2$

The vehicle reaches time is the last vehicle arrival time plus the time interval between the two.

(3) To start the service time is

$t_{1 S}=\zeta ; t_{i S}=\max \left(t_{i-1 E}, t_{i}\right), \quad i \geq 2$

Analog service start time, waiting for the vehicle to reach the team, the start time is the time to reach the maximum value of all the vehicles in front of their leave time.

(4) The waiting time

$t_{i W}=t_{i S}-t_{i}$

Vehicle waiting time is the D-value time between the times of their service reach.

(5) Completion time

$t_{i E}=t_{i S}+\eta$

If the vehicle reaches the waiting team, the vehicle's leaving time is equal to the vehicle's service start time plus service time.
(6) The total stays duration time

$t_{i t}=t_{i E}-t_{i}$

Vehicles stay in the system time is the vehicle departure time and its arrival time D-value.

(7) The number of vehicles in the queue

$l_{q i}=l_{s i}-l_{i}$

When the vehicle arrives at the team waiting, the number of vehicles in the system are the number of queue waiting in line vehicles and the number of vehicles being serviced sum.

\subsection{Vehicles Queuing System Simulation in MATLAB}

From the modeling process of system model, the model is based on the Monte Carlo method statistical mathematical simulation model, which is made in the language of mathematics, this method is similar for depicting actual vehicles in urban traffic intersection and their queuing problems at the Jiangdong Road and the Hunan Road intersection in Maanshan City. Where the main features, are the input-output relationship abstracted into a mathematical expression in order to study it. Because transportation systems are nonengineering systems, so use of data collection and statistical methods are needed to generalize the model assumptions. In this case, using the idea of the system simulation and MATLAB language programming, simulation calculates the simulated value of the system of indicators.

Queuing system is a typical discrete dynamic system, which necessarily involves simulation presentation time and event-driven representation. Here, we use the idea of a static simulation to achieve $\mathrm{M} / \mathrm{M} / 1$ queuing model of the vehicles for computer simulation. The state of the queuing system in each car can be reflected by the three quantities: The previous interval of time to reach the car, waiting time in queuing to enter the intersection and through the intersection before the time. The service time and arrival time is exponentially distributed, without any other factors' impact. Waiting time before the beginning of the service will have be subjected to change by the front vehicle. Also, after a car has arrived from the end to the front of the other cars then the car will not have to wait, it can access the path directly. Conversely, if the vehicle in front of it does not end services (including 


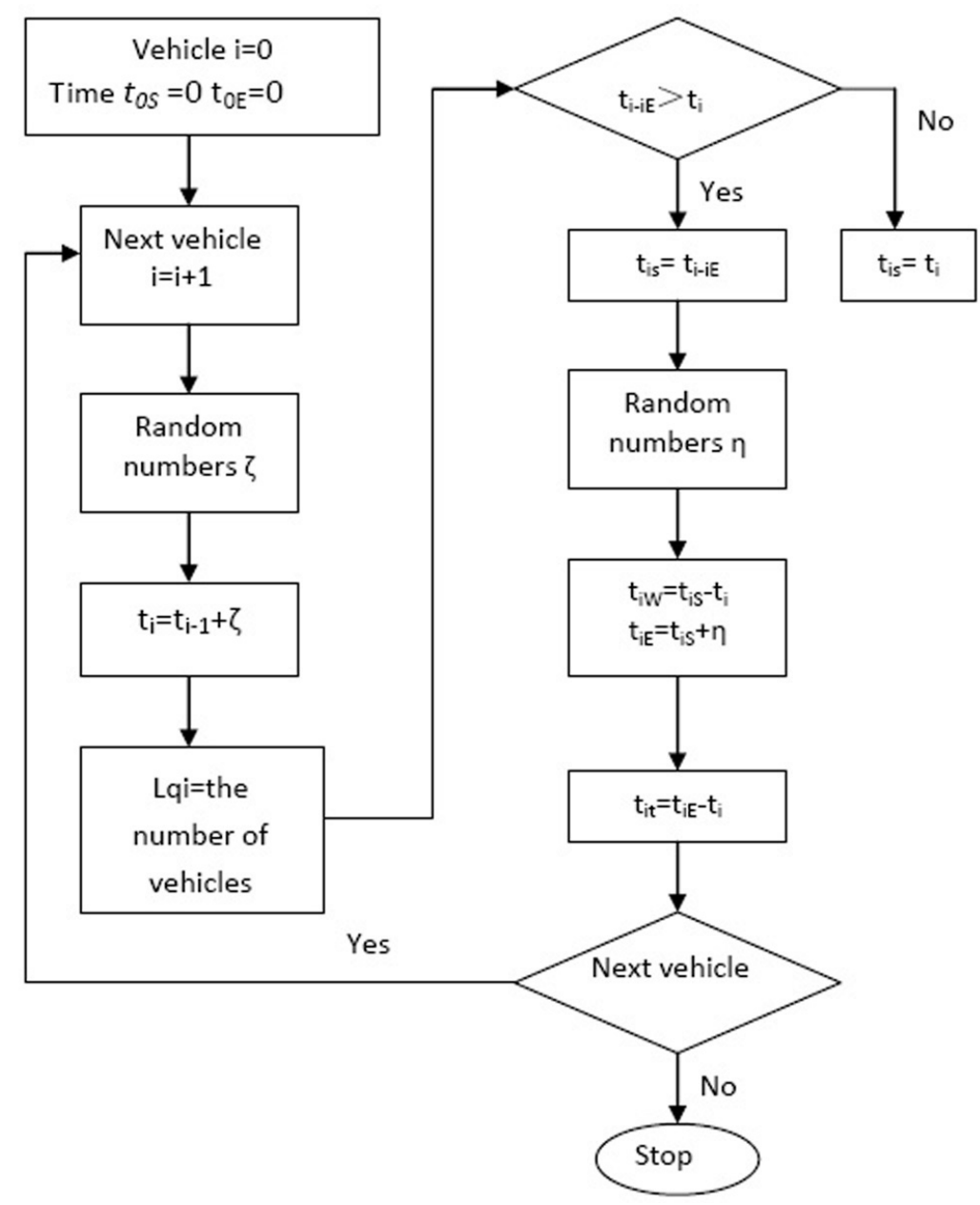

Fig. (2). Vehicles queuing model simulation logic diagram.

Table 4. Comparison table of each intersection index theory and simulated value.

\begin{tabular}{|c|c|c|c|c|c|c|c|c|c|c|}
\hline \multirow{2}{*}{$\begin{array}{c}\text { System Operation } \\
\text { Indicators }\end{array}$} & \multicolumn{2}{|c|}{ (1) Intersection } & \multicolumn{2}{|c|}{ (2) Intersection } & \multicolumn{2}{c|}{ (3) Intersection } & \multicolumn{2}{c|}{ (4) Intersection } & \multicolumn{2}{c|}{ (5) Intersection } \\
\cline { 2 - 11 } & $\begin{array}{c}\text { Theoretical } \\
\text { Value }\end{array}$ & $\begin{array}{c}\text { Analog } \\
\text { Values }\end{array}$ & $\begin{array}{c}\text { Theoretical } \\
\text { Value }\end{array}$ & $\begin{array}{c}\text { Analog } \\
\text { Values }\end{array}$ & $\begin{array}{c}\text { Theoretical } \\
\text { Value }\end{array}$ & $\begin{array}{c}\text { Analog } \\
\text { Values }\end{array}$ & $\begin{array}{c}\text { Theoretical } \\
\text { Value }\end{array}$ & $\begin{array}{c}\text { Analog } \\
\text { Values }\end{array}$ & $\begin{array}{c}\text { Theoretical } \\
\text { Value }\end{array}$ & $\begin{array}{c}\text { Analog } \\
\text { Values }\end{array}$ \\
\hline \hline $\begin{array}{c}\text { The average wait } \\
\text { Time (Sec) }\end{array}$ & 94 & 97.76 & 26.97 & 26.97 & 26.97 & 27.39 & 26.33 & 25.13 & 26.64 & 26.11 \\
\hline $\begin{array}{c}\text { Average length of stay } \\
\text { Time (Sec) }\end{array}$ & 100 & 103.3 & 33.3 & 33.3 & 33.3 & 33.84 & 33.3 & 32.17 & 33.3 & 33.27 \\
\hline $\begin{array}{c}\text { The average number of } \\
\text { vehicles } \boldsymbol{L}_{\mathrm{s}}\end{array}$ & 17 & 17.35 & 4.3 & 4.36 & 4.3 & 4.37 & 3.7 & 3.75 & 4 \\
\hline Service intensity & 0.94 & 0.93 & 0.81 & 0.81 & 0.81 & 0.82 & 0.79 & 0.79 & 0.80 & 0.80 \\
\hline
\end{tabular}

no started), then, the car's waiting time depends on the last car's ended service moment minus it's arrived time.

Through establishment of the simulation model that can be made based on the Monte Carlo method queuing $\mathrm{M} / \mathrm{M} / 1$ vehicle model simulation logic shown in Fig. (2).

According to observational data, using simulation model to simulate the various junctions and theoretical calculations, we can draw the intersection index theory and simulated values such as shown in Table 4.

\subsection{Simulation Analysis}

Through theoretical calculations and computer simulations of system operation indicators can be seen, the theoretical value and the analog value is almost the same, and found during the inspection and the number of analog simulation, the more simulations the more theoretical values and the closer to perfect results. Finally, a verifiable model of the system has been established which can accurately represent the actual system. 
Also, the data in Table 4 shows that: The first intersection operation index has distinctions more than others, the junction strength of service one is $94 \%$, indicating that the available probability of intersection one is only $6 \%$, the probability in the system of the vehicle which must wait is $94 \%$, which result in more vehicle waiting for a longer period of time. While the remaining four junction operation indicators distinction is not very obvious, the actual measurement data process allows for errors. Theoretically the service desk utilization ratio is, the higher the better, but higher utilization ratio causes more pressure at the service desk, the probability of a vehicle waiting increases, thus causing unreasonable amount of funds to be spent on the intersection's construction. After a lot of tests and verification, the best services was about $70 \%$, and service intensity intersection 2, 3, 4, 5 were about $80 \%$, so there is still room for improvement. Keeping the overall analysis in view, the strength of the junction one services are more than the rest of the four junctions service intensity is $14 \%$ more, the number of vehicles for waiting is more than $13 \%$, the average waiting time of vehicles is more than $67 \%$, the entire intersection outlet is arranged unevenly, as a result intersection one should be seen as an improving object and as a focus point.

\section{CONCLUSION}

Papers from status the vehicle queuing problems between Jiangdong Road and Hunan Road intersection analysis, focusing on the queuing theory combined with the knowledge, for using the $\mathrm{M} / \mathrm{M} / 1$ queuing model in order to investigate the improvements that can be made regarding the urban traffic congestion and vehicle queuing at the intersections. This paper through mathematical models establishes a rational, quantitative method to calculate the queuing system indicators. This paper has used Monte Carlo's method to generate random numbers, combined with the MATLAB language to realization the intersection vehicles queuing system simulation. The papers' positive result can improve the traffic situation intersection, to provide a reference for the administrative decisions of government departments in the city.

There are some issues that further require research and development. For example, the paper only presents multiintersection theoretical calculations and simulations, and haven't had extensive real-world applications, there are some potential problems which need to be settled and improved. Also, solving the intersection vehicles queuing problem is not the only a traffic problem at hand. There are also a number of problems related to economics, social, government, population, environment and technology.

\section{CONFLICT OF INTEREST}

The authors confirm that this article content has no conflict of interest.

\section{ACKNOWLEDGEMENTS}

This research is supported by the National Natural Science Foundation of China (No. 71271138), and the Humani- ties and Social Sciences Youth Fund of Ministry of Education (No. 14YJC630119), and the Major Project of Humanities and Social Sciences of the Education Department of Anhui Province (No. SK2014ZD016).

\section{ABOUT THE AUTHORS}

First Author Wang Fu-yu was born in Henan Province, China, in 1977. He is currently an associate professor at Anhui University of Technology, Anhui, China. He obtained a first class Bachelor's degree in 1999 and a Master's degree in 2005 from China University Of Petroleum, Shandong, China. And he's studying for his doctorate at University of Shanghai for Science and Technology, Shanghai, China. His research interests include Industrial Engineering and Intelligent Optimization.

Second Author Ye Chun-Ming was born in Anhui Province, China, in1964. He is currently a professor and doctoral tutor at University of Shanghai for Science and Technology, Shanghai, China. His research interests include Industrial Engineering, Intelligent Optimization and Production Scheduling.

Third Author Zhang Ya-nan was born in Anhui Province, China, in 1991 . He is currently a graduate student at Anhui University of Technology, Anhui, China. He received his BEng degree in Industrial Engineering from Anhui University of Technology in 2013. His research interests include Industrial Engineering and Intelligent Optimization.

Fourth Author Li yan was born in Anhui Province, China, in 1984. She is currently a lecturer at Anhui University of Technology, Anhui, China. She received her BEng degree in Industrial Engineering from Anhui University of Technology in 2008. Her research interests include Industrial Engineering and Game Analysis.

\section{REFERENCES}

[1] X. Z. Zhou, Z. Liu and H. X. Zhang, "Model of Traffic travel, OD, path allocation and charging Pricing in the network of traffic congestion," Journal of Systems Management, vol.4, no. 2, pp.180-184, 2007.

[2] X. Su and S. J. Yuan, "Analysis of traffic management planning in small city," Shanxi Architecture, vol.37, no. 28, pp.16-17, 2011.

[3] Y. F. Wang, "Status of intelligent transportation systems at home and abroad," Silicon Valley, vol. 23, pp.181-181, 2008.

[4] L. Redman, M. Friman, T. Gärling, "Quality attributes of public transport that attract car users: A research review," Transport. Pol$i c y$, vol. 25, pp. 119-127, 2013.

[5] M. Friskb, M. Göthe-Lundgrenc, K. Jörnstena, "Cost allocation in collaborative forest transportation," European Journal of Operational Research, vol. 205, no. 2, pp. 448-458, 2010.

[6] S. S. Ivey, "Review of Policies on Access to Transportation Planning Data and Models: Implications for Transportation Planning Agencies," Journal of Urban Planning and Development, vol. 137, no. 4, pp.438-447, 2011.

[7] P. Waddella, "Integrated Land Use and Transportation Planning and Modeling: Addressing Challenges in Research and Practice," Transport Reviews: A Transnational Trans disciplinary Journal, vol. 31, no. 2, pp.209-229, 2011

[8] M.D. Meyer, E. J. Miller, "Urban transportation planning: A decision-oriented approach", McGraw-Hill, Incorporated, Feb. 2001.

[9] A. A. Lokhandwala, "Analysis of demand variability and robustness in strategic transportation planning, "Massachusetts Institute of Technology. Reference: Available from: Http:/hdl.handle.net/ 1721.1/61003.2010. 
[10] L. X. Yang, Z. Y. Gao and K.P. Li, "Railway freight transportation planning with mixed uncertainty of randomness and fuzziness," Applied Soft Computing, vol. 11, no. 1, pp.778-792, 2011.

[11] X. P. Yan, X. F. Ma and G.H. Huang," An inexact transportation planning model for supporting vehicle emissions management", Journal of Environmental Informatics, vol.15, no. 2, pp. 87-98, 2010.

Received: September 22, 2014

Revised: November 30, 2014

Accepted: December 02, 2014

(C) Wang et al.; Licensee Bentham Open.

This is an open access article licensed under the terms of the Creative Commons Attribution Non-Commercial License (http://creativecommons.org/licenses/by-nc/3.0/) which permits unrestricted, non-commercial use, distribution and reproduction in any medium, provided the work is properly cited. 